\title{
Artificial Neural Network Applied for Detecting the Saturation Level in the Magnetic Core of a Welding Transformer
}

\author{
Klemen Deželak ${ }^{1}$, Gorazd Štumberger ${ }^{1}$, Drago Dolinar ${ }^{1}$ and Beno Klopčič ${ }^{2}$ \\ 1 University of Maribor, Faculty of Electrical Engineering and Computer Science \\ Indramat elektromotorji d. o. o. \\ Slovenia
}

\section{Introduction}

This chapter deals with the detector of saturation level in the magnetic (iron) core of a welding transformer. It is based on an artificial neural network (ANN) and requires only the measurement of the transformer's primary current. The saturation level detector could be the substantial component of a middle frequency resistance spot welding system (RSWS), where the welding current and the flux density in the welding transformer's iron core are closed-loop controlled by two hysteresis controllers. The resistance spot welding systems, described in different realizations (Brown, 1987), are widely used in the automotive industry. Although the alternating or direct currents (DC) can be used for welding, this chapter focuses on the resistance spot welding system (Fig. 1) with DC welding current. The resistances of the two secondary windings $R_{2}, R_{3}$ and characteristics of the rectifier diodes, connected to these windings, can slightly differ. Reference (Klopčič et al., 2008) shows that combination of these small differences can result in increased DC component in welding transformer's iron core flux density. It causes increasing iron core saturation with the high impact on the transformer's primary current $i_{1}$, where currents spikes eventually appear, leading to the over-current protection switch-off of the entire system. However, the problematic current spikes can be prevented either passively or actively (Klopčič et al., 2008). When the current spikes are prevented actively, closed-loop control of the welding current and iron core flux density is required (Klopčič et al., 2008). Thus, the welding current and the iron core flux density must be measured. While the welding current is normally measured by the Rogowski coil (Ramboz, 1996), the iron core flux density can be measured by the Hall sensor or by a probe coil wound around the iron core. In the case, the flux density value is obtained by the analogue integration of the voltage induced in the probe coil (Deželak et al., 2008). Integration of the induced voltage can be unreliable due to the unknown integration constant in the form of the remanent flux and the drift in analogue electronic components. The drift can be kept under control by the use of closed-loop compensated analogue integrator.

An advanced, the two hysteresis controllers based control of the RSWS, where the current spikes are prevented actively by the closed-loop control of the welding current and flux 
density in the welding transformer's iron core, is presented in (Klopčič et al., 2008). The modified solution requires measuring of the welding current, while instead of measured flux density only information about saturation level in the iron core is required (Deželak et al., 2010). Some methods, tested on welding transformer's iron core, that can be applied for saturation level detection are presented in (Deželak et al., 2008). All these methods require the Hall sensor or probe coils which make them less interesting for applications in the industrial RSWS, due to the relatively high sensitivity on vibrations, the mechanical stresses and the high temperatures. In order to overcome these problems, an ANN based iron core saturation level detector is introduced in this work. Additionally the method proposed for the detecting saturation level of the complete loaded RSWS, completed by ANN, is presented. Its only (single) input is the measured transformer's primary current.

The ANN, applied in the iron core saturation level detector, is trained to recognize the waveform of the current spikes, which appear in the primary current when the iron core is approaching the saturated region. Before the ANN can be applied, its structure must be defined first, and then the ANN must be trained using an appropriate learning method (Pihler et al., 1997). In this paper, the ANN structure appropriate for saturation detection in the transformer's iron core and the appropriate learning method are found with the help of properly build dynamic model of the RSWS (Deželak et al., 2010). The mentioned dynamic model includes models of the hysteresis controllers and the ANN based saturation level detector. The well-known trial and error method was used for defining ANN structure. It is shown that the three-layer ANN with 30 neurons in the first layer, 7 neurons in the second layer, and 1 neuron in the third layer, gives acceptable results. ANN is trained by the resilient backpropagation rule, where the measured and calculated samples of transformer's primary current, with different known levels of saturation in the iron core, are used. The calculated and measured results, presented in this paper, show that the proposed ANN based iron core saturation level detector can be used as a part of the discussed RSWS, improving performances of the entire system

\section{Dynamic model of the resistance spot welding system}

The resistance spot welding system consists of a full wave output rectifier, a single phase transformer, an H-bridge inverter and an input rectifier. It is shown in Fig. 1 and described in (Klopčič et al., 2008). The three-phase alternating current (AC) voltages $u_{1}, u_{2}$ and $u_{3}$, supplied from the electric grid, are rectified in the input rectifier in order to produce the DC bus voltage. This voltage is used in the H-bridge inverter, where different switching patterns and modulation techniques can be applied, to generate AC voltage $u_{\mathrm{H}}$, required for supply of the welding transformer. The welding transformer has one primary and two secondary windings. They are marked with indices 1, 2 and 3, respectively. The currents, the number of turns, the resistances and the leakage inductances of the primary and two secondary welding transformer's windings are denoted by $i_{1}, i_{2}, i_{3}, N_{1}, N_{2}, N_{3}, R_{1}, R_{2}, R_{3}$, and $L_{\sigma 1}, L_{02}, L_{03}$. The effects of the eddy current losses are accounted for by the resistor $R_{\mathrm{Fe}}$, while $R_{\mathrm{L}}$ and $L_{\mathrm{L}}$ are the resistance and inductance of the load. The output rectifier diodes $D_{1}$ and $D_{2}$ are connected to both transformer's secondary coils. They generate the DC welding current $i_{L}$ which has a DC value a few times higher than the amplitudes of AC currents $i_{2}$ and $i_{3}$ that appear in the transformer's secondary coils without rectifier diodes. 


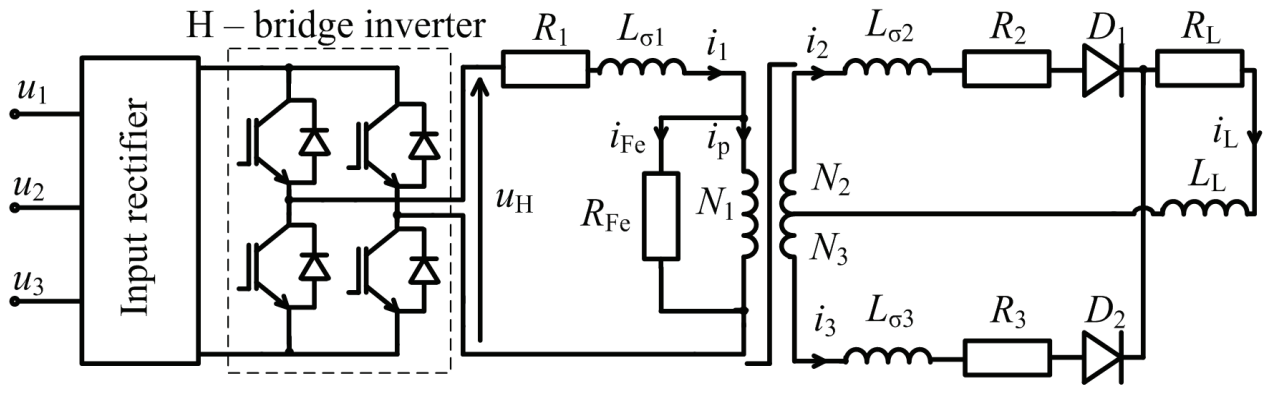

Fig. 1. The resistance spot welding system

The supply voltage of the primary coil of the transformer could be generated on the different ways (Štumberger et al., 2010). In the existent system, widely spread in the automotive industry, this voltage is generated by the H-bridge inverter applying pulse width modulation (PWM) at switching frequency of $f=1 \mathrm{kHz}$. The PWM principle is shown in Fig. $2 \mathrm{a}$, where $u_{\mathrm{t}}$ is the triangular voltage, $U_{\text {ref }}$ is the reference voltage for PWM, $T_{\mathrm{p}}$ is the period of H-bridge inverter output voltage, $u_{\mathrm{m}}$ is the gate driver input voltage, $S_{1}, S_{4}$ and $S_{2}$, $S_{3}$ are the pairs of IGBT-s in the H-bridge inverter (Sabate et al., 1990).

Additionally Fig. $2 \mathrm{~b}$ shows the AC voltage generated by the H-bridge applied by PWM, where $U_{\mathrm{DC}}$ is the DC-bus voltage.

a)

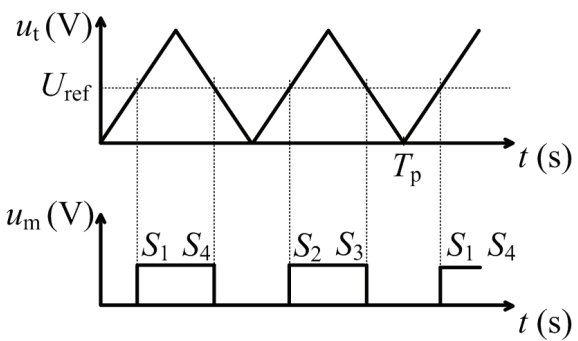

b)

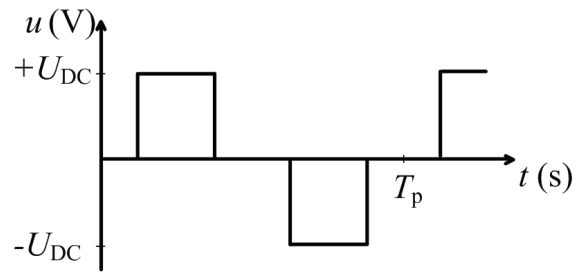

Fig. 2. The PWM principle (a) and the AC voltage generated by the H-bridge applied by PWM (b)

As references (Klopčič et al., 2008) and (Deželak et al., 2010) show, the resistances of the secondary windings $R_{2}, R_{3}$ and the characteristics of the rectifier diodes could be slightly different. These differences can cause DC component in welding transformer's iron core flux density, which causes increasing iron core saturation with the essential impact on the transformer's primary current $i_{1}$, where currents spikes appear, leading to the over-current protection switch-off of the entire system.

Aforementioned phenomena could be confirmed by the appropriate dynamic model (Leon \& Semlyen, 1994) of the complete resistance spot welding system. In this work the model is built with the programme package Matlab/Simulink based on the following set of equations (1) $-(8)$. 


$$
\begin{gathered}
u_{\mathrm{H}}=R_{1} i_{1}+L_{\mathrm{\sigma} 1}\left(d i_{1} / d t\right)+N_{1}(d \phi / d t) \\
0=R_{2} i_{2}+L_{\mathrm{o} 2}\left(d i_{2} / d t\right)+N_{2}(d \phi / d t)+d i_{1}+R_{\mathrm{L}} i_{\mathrm{L}}+L_{\mathrm{L}}\left(\mathrm{d}\left(i_{2}+i_{3}\right) / d t\right) \\
0=R_{3} i_{3}+L_{\mathrm{o} 3}\left(d i_{3} / d t\right)-N_{3}(d \phi / d t)+d i p_{2}+R_{\mathrm{L}} i_{\mathrm{L}}+L_{\mathrm{L}}\left(d\left(i_{2}+i_{3}\right) / d t\right) \\
N_{1} i_{\mathrm{p}}+N_{2} i_{2}-N_{3} i_{3}=H(B) l_{\mathrm{ic}}+2 \delta B / \mu_{0} \\
i_{\mathrm{L}}=i_{2}+i_{3} \\
i_{1}=i_{\mathrm{Fe}}+i_{\mathrm{p}} \\
i_{\mathrm{Fe}}=N_{1}(d \phi / d t) / R_{\mathrm{Fe}} \\
\phi=B A_{\mathrm{Fe}} \\
\theta=N_{1} i_{1}+N_{2} i_{2}-N_{3} i_{3}
\end{gathered}
$$

In set of equations (1) - (8) $\phi$ stands for magnetic flux, dip 1 and dip $p_{2}$ are nonlinear characteristics of the output rectifier diodes $D 1$ and $D_{2}, H(B)$ is the magnetizing curve of the iron core material, $\delta$ is the air gap, $B$ is the iron core flux density, $\mu_{0}$ is the permeability of the vacuum, $l_{\mathrm{ic}}$ is the average length of the magnetic flux line in the iron core, $A_{\mathrm{Fe}}$ is the crosssection of the transformer's iron core and $\theta$ is the magnetomotive force. Parameters that appear in (1) - (8) are shown in Table 1 and in Table 2.

\begin{tabular}{|c|c|c|}
\hline Parameter & Value & Unit \\
\hline $\mathrm{A}_{\mathrm{Fe}}$ & 0.001385 & $\mathrm{~m}^{2}$ \\
\hline$\delta$ & 10 & $\mu \mathrm{m}$ \\
\hline $\mathrm{l}_{\mathrm{ic}}$ & 0.313 & $\mathrm{~m}$ \\
\hline $\mathrm{f}$ & 1000 & $\mathrm{~Hz}$ \\
\hline $\mathrm{R}_{1}$ & 0.01357 & $\Omega$ \\
\hline $\mathrm{R}_{2}$ & 20 & $\mu \Omega$ \\
\hline $\mathrm{R}_{3}$ & 20 & $\mu \Omega$ \\
\hline $\mathrm{R}_{\mathrm{L}}$ & 100 & $\mu \Omega$ \\
\hline $\mathrm{L}_{\mathrm{o} 1}$ & 0.035 & $\mathrm{mH}$ \\
\hline $\mathrm{L}_{\mathrm{o} 2}$ & 1 & $\mathrm{nH}$ \\
\hline $\mathrm{L}_{03}$ & 1 & $\mathrm{nH}$ \\
\hline $\mathrm{L}_{\mathrm{L}}$ & 1 & $\mu \mathrm{H}$ \\
\hline $\mathrm{N}_{1}$ & 55 & $/$ \\
\hline $\mathrm{N}_{2}$ & 1 & $/$ \\
\hline $\mathrm{N}_{3}$ & 1 & $/$ \\
\hline
\end{tabular}

Table 1. Parameters of RSWS dynamic model 


\begin{tabular}{|c|c|c|c|}
\hline$d i p_{1}-i(A)$ & $d i p_{1}-u(V)$ & $d i p_{2}-i(A)$ & $d i p_{2}-u(V)$ \\
\hline 0 & 0 & 0 & 0 \\
\hline 0.003 & 0.6 & 0.011 & 0.6 \\
\hline 0.014 & 0.65 & 0.053 & 0.65 \\
\hline 0.059 & 0.7 & 0.25 & 0.7 \\
\hline 0.247 & 0.75 & 1.17 & 0.75 \\
\hline 1.05 & 0.8 & 5.52 & 0.8 \\
\hline 4.43 & 0.85 & 25.9 & 0.85 \\
\hline 18.75 & 0.9 & 121.5 & 0.9 \\
\hline 79.3 & 0.95 & 570 & 0.95 \\
\hline 335 & 1 & 2675 & 1 \\
\hline 1418 & 1.05 & 12555 & 1.05 \\
\hline 6000 & 1.1 & 58912 & 1.1 \\
\hline 25378 & 1.15 & 400416 & 1.15 \\
\hline 107334 & 1.2 & 1297043 & 1.2 \\
\hline
\end{tabular}

Table 2. Nonlinear characteristics of the output rectifier diodes $D_{1}-\left(d i p_{1}\right)$ and $D_{2}$ - (dip $p_{2}$

With the appropriate dynamic model the two behaviours of RSWS, the symmetrical and asymmetrical, could be simulated. Firstly, the symmetrical behaviour is considered by parameters shown in Table 3, while obtained results are shown in Fig. 3. The resistances $R_{2}$ and $R_{3}$ in the two secondary welding transformer's windings are equal, as well the characteristics of the output rectifier diodes $D_{1}$ and $D_{2}$. Fig. 3 shows the time dependent primary current $i_{1}$ and the magnetic flux density $B$ in the time window of $t=0.1 \mathrm{~s}$.

\begin{tabular}{|c|c|c|}
\hline Parameter & Value & Unit \\
\hline $\mathrm{R}_{2}$ & 20 & $\mu \Omega$ \\
\hline $\mathrm{R}_{3}$ & 20 & $\mu \Omega$ \\
\hline $\mathrm{D}_{1}$ & characteristic - dip & $/$ \\
\hline $\mathrm{D}_{2}$ & characteristic - dip & $/$ \\
\hline
\end{tabular}

Table 3. Parameters for symmetrical behaviour of the resistance spot welding system

Different resistances $R_{2}$ and $R_{3}$ and different characteristics of the output rectifier diodes $D_{1}$ and $D_{2}$ could cause undesired asymmetry of the spot welding system. In case of considering values shown in Table 4, the asymmetrical time dependent magnetic flux density $B$ could be obtained by the appropriate model of RSWS. In this way, when the magnetic flux density $B$ reaches the saturation level the current spikes appear in the primary current $i_{1}$, as shown in Fig. 4.

\begin{tabular}{|c|c|c|}
\hline Parameter & Value & Unit \\
\hline $\mathrm{R}_{2}$ & 20 & $\mu \Omega$ \\
\hline $\mathrm{R}_{3}$ & 15 & $\mu \Omega$ \\
\hline $\mathrm{D}_{1}$ & characteristic - dip & $/$ \\
\hline $\mathrm{D}_{2}$ & characteristic - dip & $/$ \\
\hline
\end{tabular}

Table 4. Parameters for asymmetrical behaviour of the resistance spot welding system 

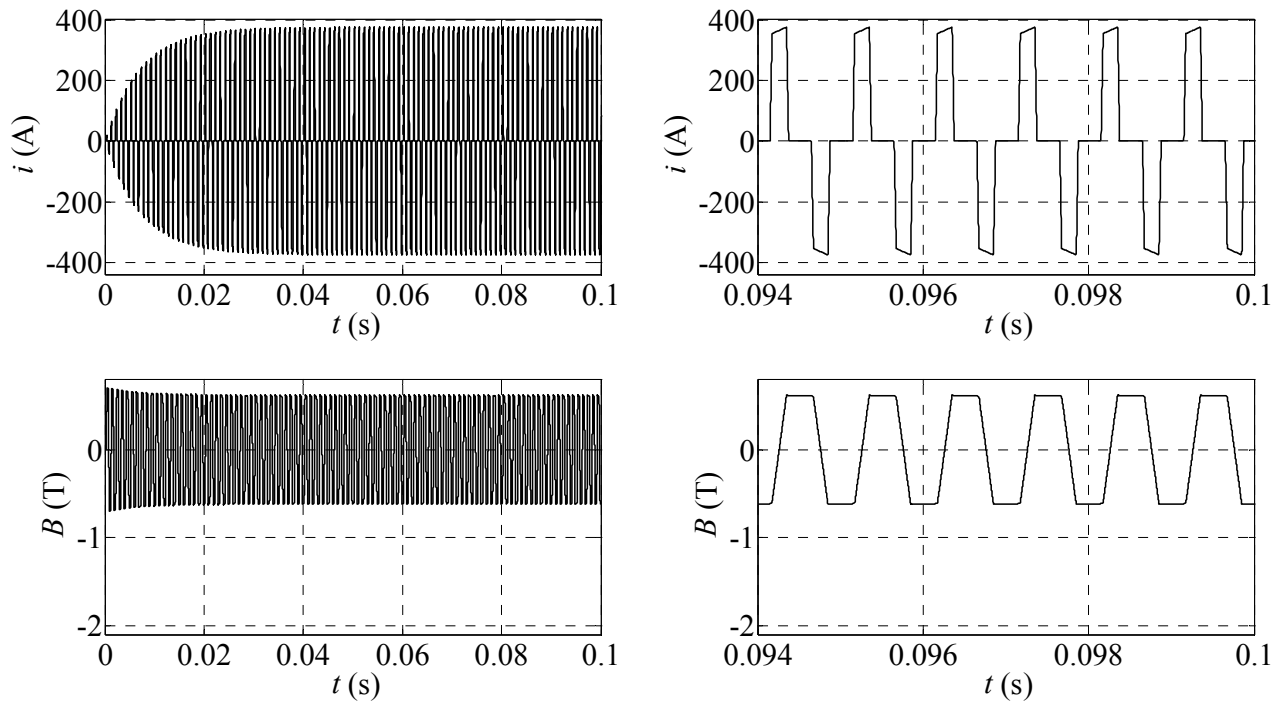

Fig. 3. Symmetrical behaviour of the resistance spot welding system
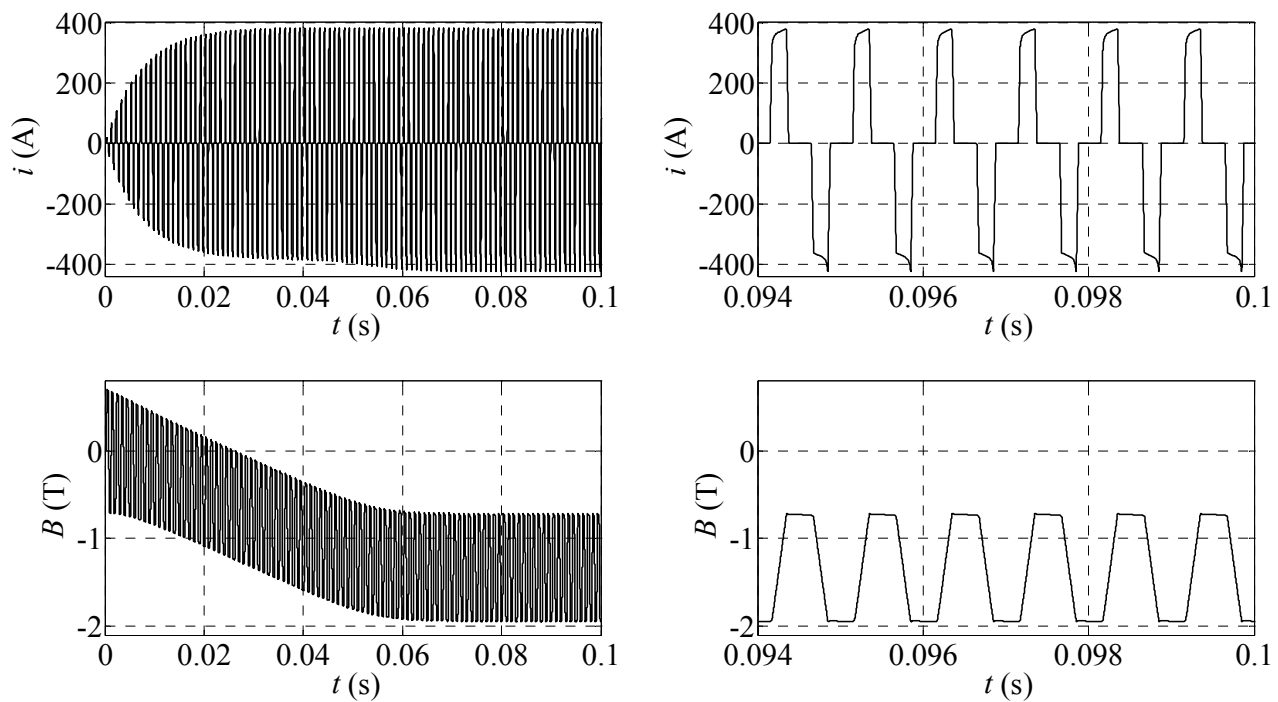

Fig. 4. Asymmetrical behaviour of the resistance spot welding system

As Fig. 4 shows, the iron core becomes more and more saturated, which leads to currents spikes in the primary current $i_{1}$ and finally to the over-current protection switch-off. The unwanted current spikes can be prevented passively by using pairs of rectifier diodes with matched characteristics, or actively (Klopčič et al., 2008) by controlling the saturation level in the iron core. In the letter case, a saturation detector, which generates a signal when the preset saturation level is reached, is indispensable for preventing the iron core saturation. 
This work evaluates the methods appropriate for the detecting saturation level in the stand alone transformer's iron core and in the transformer operating in the resistance spot welding system. These methods actually detect the instant when the iron core starts to become saturated and generate signals which are used in the control algorithm to prevent iron core saturation. All of the presented methods are based on the ANN which is applied as an additionally tool for the detection of transformer's core saturation.

\section{The detecting saturation level in the transformer's iron core}

In this section, the saturation level detection of the stand alone transformer's iron core, is described (Deželak et al., 2008). The iron core of a welding transformer, which is normally installed in an industrial resistance spot welding system, is shown in Fig. 5. For test purposes, the actual primary and secondary windings were replaced with only one primary coil, which was able to produce the same magnetomotive force as the primary and secondary winding, together. In Fig. $5, u$ denotes the primary voltage, $i_{1}$ is the primary current, $\delta$ is the length of the air gap, while $A_{\mathrm{Fe}}$ is the cross-section of the iron core. A measurement coil is wound around the iron core for measurement purposes. The primary and measurement coils have the same number of turns $N$.
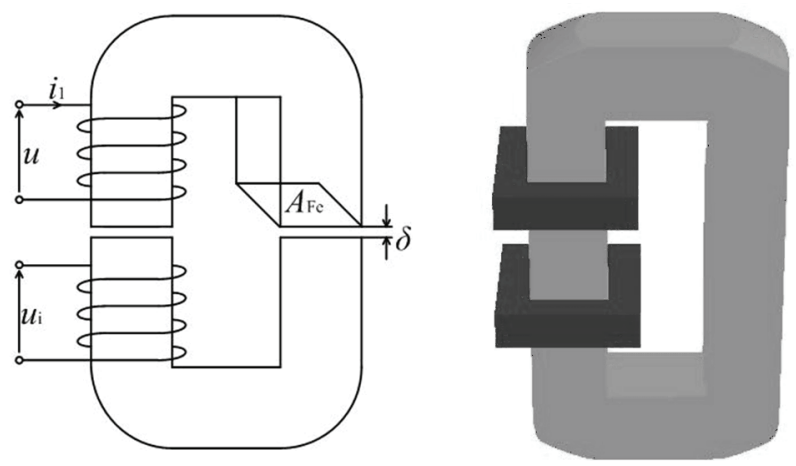

Fig. 5. The iron core of a welding transformer

The proposed method is based on calculation of dynamic inductance $L_{\mathrm{d}}(9)$, where $u$ is the measured induced voltage (10) and $i$ is the measured transformer's primary current. Fig. 6 shows the dynamic inductance as a function of primary current $i$. The dynamic inductance is defined by (11), where $\psi(i)$ is the magnetically nonlinear iron core characteristic shown in Fig. 6. In the given case, the magnetically nonlinear characteristic of the welding transformer's iron core $\psi(i)$ was determined experimentally using numerical integration (12).

$$
\begin{gathered}
L_{\mathrm{d}}=u /(d i / d t) \\
u=d \psi / d t \\
L_{\mathrm{d}}=\partial \psi / \partial I \\
\psi(t)=\psi(0)+\int\left(u(\tau)-R_{1} i(\tau)\right) d \tau
\end{gathered}
$$


In (12) $\psi(t)$ is the time behaviour of the flux linkage, $i_{1}(t)$ and $u(t)$ are the measured primary current and voltage, while $R_{1}$ stands for the resistance of the primary winding.

a)
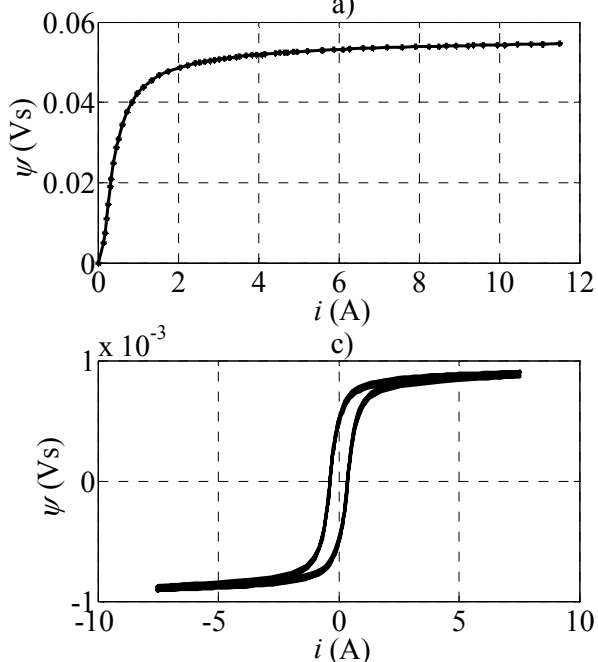

b)

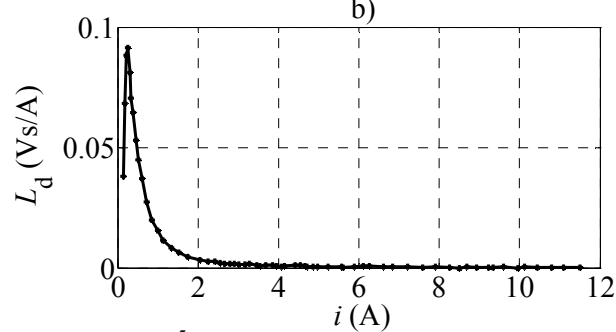

d)

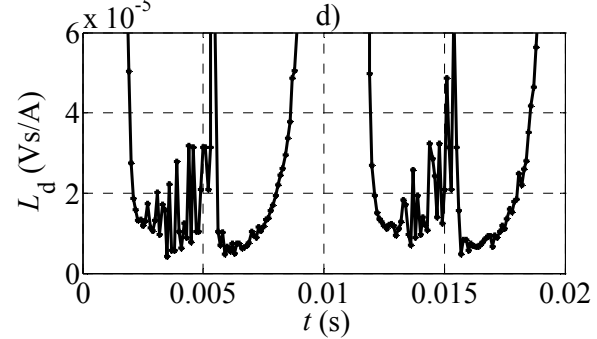

Fig. 6. The dynamic inductance and magnetically nonlinear iron core characteristic

When the value of dynamic inductance $L_{\mathrm{d}}(i)$, shown in Fig. 6b, drops under the value of $L_{\mathrm{d}}(i)$ $=0.0003 \mathrm{Vs} / \mathrm{A}$, which is reached at $i=8 \mathrm{~A}$, the iron core can be considered as saturated. However, the signal that represents dynamic inductivity $L_{d}(i)$ calculated by (9) is contaminated with noise, as shown in Fig. 6d. The contamination with the noise is substantially increased in the vicinity of the reversal points of the hysteresis, which makes reliable iron core saturation level detection almost impossible.

This problem can be effectively solved by supplementing the calculated values of the dynamic inductivity in the vicinity of the reversal points of the hysteresis by a signal generated by an artificial neural network. The artificial neural network is a parallel multi layer information processing structure, with possibility to include expert knowledge into existent process. Fig. 7 shows the three-layer artificial neural network, where $\mathrm{x}_{1}, \mathrm{x}_{2}, \ldots$ stand for input parameters or signals, $\mathrm{w}\left(\mathrm{x}_{1}\right)_{1}, \mathrm{w}\left(\mathrm{x}_{2}\right)_{2}, \mathrm{w}\left(\mathrm{x}_{1}\right)_{2}, \mathrm{w}\left(\mathrm{x}_{2}\right)_{2}, \ldots, \mathrm{w}_{56}$ are the weight coefficients, $1,2,3, \ldots, 6$ are the sum blocks, while $\tan _{\text {sig }}$ and lin stand for the sigmoid and linear activation functions. Additionally $z_{1}, z_{2}, z_{3}, \ldots, z$ are the output signals of the sum blocks, while $y_{1}, y_{2}, y_{3}, \ldots, y$ are output signals of the neurons (Hassoun, 1995). The number of neurons used in the three-layer artificial neural network shown in Fig. 7 is six - three in the first layer, 2 in the second layer and 1 in the output layer. The neural network can be supplemented with the bias vector for the each individual neuron. The artificial neural networks accumulate the knowledge during the training process, while the effectiveness of the artificial neural network depends on the quality of the training procedure. The fundamental aim of the training procedure is to adjust all weights in artificial neural network to obtain minimal deviations between the target and calculated outputs (Hoyong et al., 1993). 


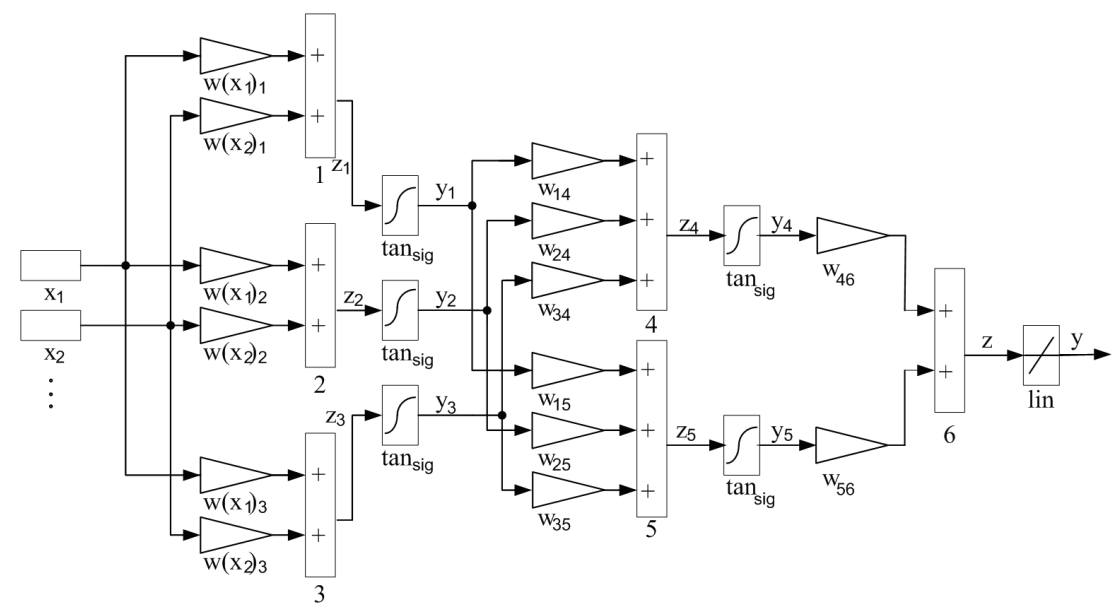

Fig. 7. The example of the three layers artificial neural network

In this chapter the error backpropagation method is applied. For that reason the characteristic input patterns must be selected, while the target signal is generated with respect to the input patterns. Training with the error backpropagation learning rule consists of the initialization of all weights (and bias) with randomly selected initial values and calculations of all outputs signals from each neuron. As soon as the output value of the last neuron in the output layer is calculated, the squared error for this (last) neuron can be calculated and then errors for the rest of neurons, from the output layer towards the input layer can be defined too. Finally, when errors of each neuron are obtained, the new values of all weights (and bias) can be calculated and the entire procedure can start with the new iteration. The number of iterations of described procedure is called the number of epochs. The iterations stop when the error reaches predefined value or the maximal number of epochs (iterations) is reached. In the given case, the learning signal was build of 170 patterns (signals) obtained by measurements, while the target signal was defined afterwards and was set to the values one (saturated) or zero (not saturated). Fig. 8 shows five of these patterns. In the case when the value of the target signal (Tar.) equals one, the iron core is considered as saturated. After extensive testing of different net configurations, the final artificial neural network configuration was defined. It contains three-layer with 50 neurons in the first layer, 8 neurons in the second - hidden layer, and with one neuron in the third - output layer.

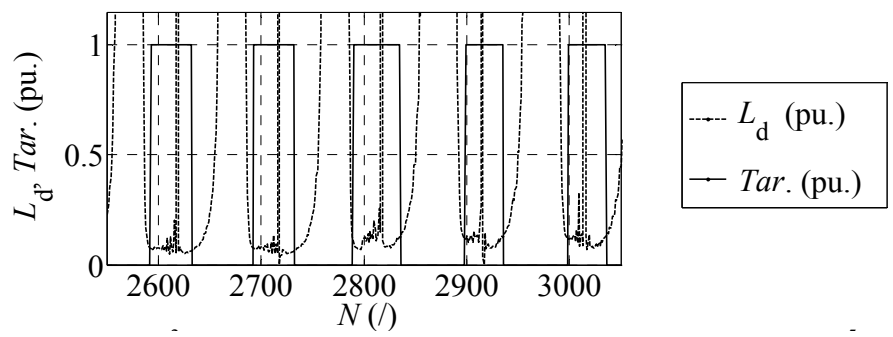

Fig. 8. The learning and targets signals in the case of the saturation level detection of the transformer's iron core 
Once the artificial neural network is trained, which means that all of the weights and bias are set, it can be tested. First with the patterns used in the training procedure (Fig. 9 left) and then with the new samples which were not used in the training procedure (Fig. 9 right). Results presented in Fig. 9 show that the artificial neural network trained in this way is appropriate for saturation level detection in the transformer's iron core. However, the results of extended analysis showed that the proposed method gives unreliable results when the level of iron core saturation further increases. Fig. 10 shows the results obtained by the artificial neural network for the case when transformer's iron core was highly saturated. Fig. 10 shows output signal of artificial neural network before $(\mathrm{Out})$ and after $\left(\mathrm{Out} \mathrm{t}^{\prime}\right)$ the final bias value $\left(O u t^{\prime}=0\right.$ means iron core is not saturated, $O u t^{\prime}=1$ means iron core is saturated). According to the artificial neural network output signals the highly saturated iron core is not saturated at all.

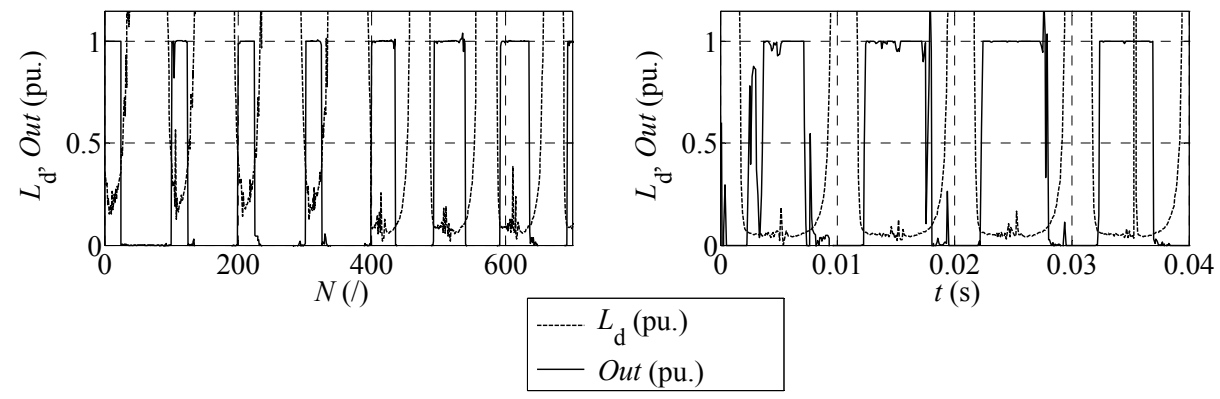

Fig. 9. Testing of the ANN with the patterns used in the training procedure (left) and with the new samples which were not used in the training procedure (right)

The results presented show that the artificial neural network is not reliable enough to be used for iron core saturation level detection as a stand alone algorithm. However, it could be very useful as a supplement to the existing algorithms for iron core saturation detection which fails when approaching reversal point on the hysteresis loop. In this region the artificial neural network can provide reliable information that the system is approaching reversal point of the hysteresis loop, which can be used to stabilize existing algorithms for iron core saturation level detection.

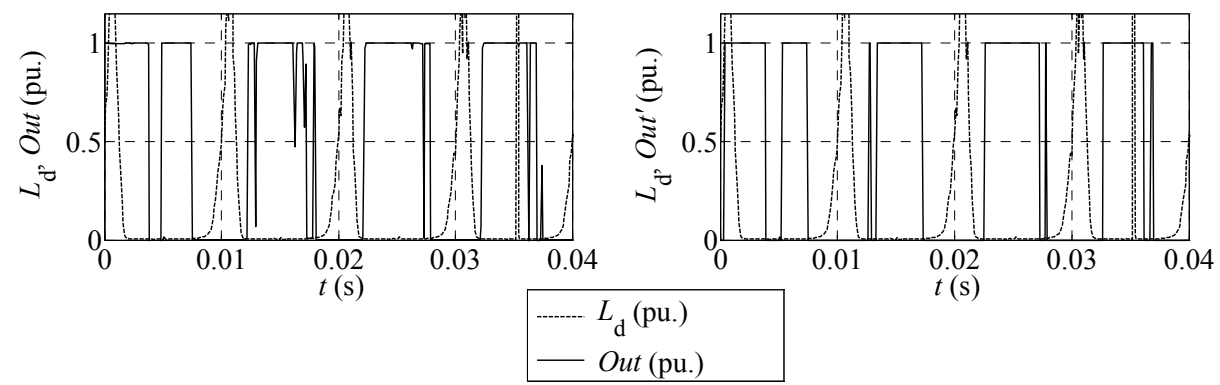

Fig. 10. Testing of the ANN with the patterns of the highly saturated transformer's iron core before Out (left) and after Out' (right) the final bias value 


\section{The detecting saturation level in the resistance spot welding system}

Now the algorithm for detecting the saturation level in the iron core of the transformer operating in the resistance spot welding system can be presented. One of the possible solutions for active prevention of the current spikes, is the closed-loop control of the iron core flux density and welding current with two hysteresis controllers (Klopčič et al., 2008). Thus, the iron core flux density and the welding current must be measured. The iron core flux density can be measured by the Hall sensor or by a probe coil wound around the iron core, while the welding current is normally measured by the Rogowski coil. The flux density value is obtained by an analogue integration of the voltage induced in the probe coil. It is well known that the integration of the induced voltage could be unreliable due to the drift in analogue electronic components and the unknown integration constant in the form of remanent flux. Because of the mentioned drawback, this work proposes an improved solution. Instead to measure the flux density only the information about the saturation level in the welding transformer's iron core is required (Fig. 11). In Fig. $11 S_{1}-S_{4}$ stand for the adequate switching of the transistors.

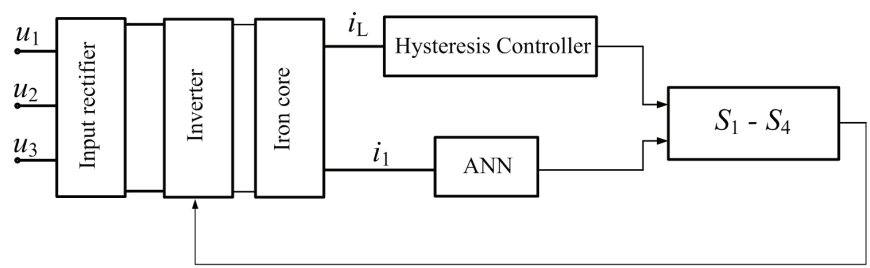

Fig. 11. The closed-loop control of the transformer primary current $i_{1}$ and welding current $i_{\mathrm{L}}$ using the hysteresis controller and the ANN

To obtain the information about the saturation level an ANN can be applied as an effective tool, where the ANN single input is the measured transformer's primary current $i_{1}$ (Deželak et al., 2010). The idea is to replace one hysteresis controller with ANN. Basically the ANN is trained to recognize the waveform of the current spikes, which appear in the primary current when the iron core is approaching the saturated region.

\subsection{Hysteresis control with saturation detector}

The $\mathrm{H}$ - bridge inverter output voltage $u_{H}$ (Fig. 1) is equal to DC voltage, while its polarity depends on the pair of transistors that are switched on. When all four transistors are switched off, the voltage $u_{H}$ equals zero. The welding current $i_{\mathrm{L}}$ increases when the primary voltage of the transformer $u_{H}$ differs from zero. On the other hand the welding current tends towards zero when $u_{H}$ equals zero. The magnetic flux density increases when +DC bus voltage is applied and decreases when-DC bus voltage is applied. As soon as the magnetic flux density exceeds its limit, the transformer's iron core becomes highly saturated, which causes current spikes in the transformer's primary current $i_{1}$. The advanced control of the RSWS can be applied to prevent the current spikes. The authors in (Klopčič et al., 2008) proposed an advanced hysteresis control of the RSWS based on two hysteresis controllers. The first one is used for the closed-loop control of the welding current while the second one is used for the closed-loop control of a flux density in the transformer's iron core. The advanced hysteresis control requires information that the preset saturation level in the iron core is exceeded. Measurement of the iron core flux density $B$ can be avoided. 
This subsection proposes an ANN based detector of saturation level in the iron core. The only input for the proposed detector is the measured welding transformer's primary current $i_{1}$. The output signal of the ANN based saturation detector (Tar.) is set to the value one when the preset saturation level in transformer's iron core is exceeded. Operation of the advanced hysteresis control, supplemented by the proposed ANN based saturation level detector, is illustrated in Fig. 12, where $i_{\mathrm{L}}$ is the welding current, $u_{\mathrm{H}}$ is the applied H-bridge inverter output voltage, and $t$ stands for the time. The upper $\left(i_{\mathrm{Lu}}\right)$ and lower $\left(i_{\mathrm{LI}}\right)$ welding current limits must be set before start.

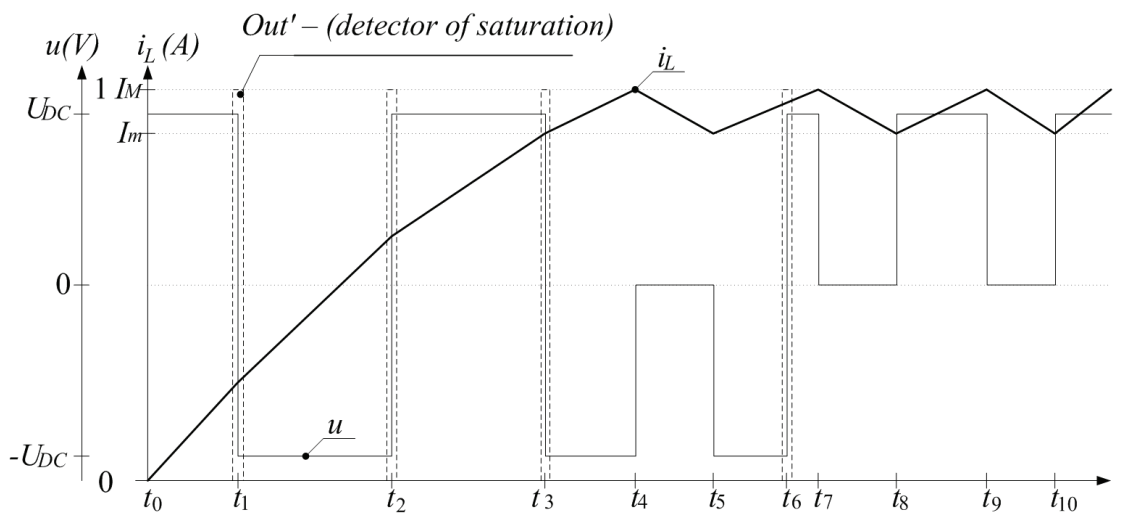

Fig. 12. Operation of the advanced hysteresis control, supplemented by the saturation level detector

The advanced hysteresis control of the RSWS, supplemented by the proposed saturation level detector, starts at the time $t=0 \mathrm{~s}$. The H-bridge inverter generated transformer's supply voltage $u_{\mathrm{H}}=U_{\mathrm{DC}}$, is applied. The welding current $i_{\mathrm{L}}$ and the iron core flux density $B$ start to increase. At the time $t_{1}$, the ANN based saturation level detector detects that the preset saturation level in the iron core is exceeded. Its output signal Out' is set to the value 1 , while the transformer's supply voltage is changed to $u_{\mathrm{H}}=-U_{\mathrm{DC}}$. The welding current still increases while the iron core flux density starts to decrease. At time $t_{2}$, the saturation level detector detects the exceeded saturation level again. In this case, it is caused by a high negative value of the iron core flux density. The transformer's supply voltage changes to $u_{\mathrm{H}}=U_{\mathrm{DC}}$. The welding current still increases while the flux density value starts to increase again.

Thus, whenever the ANN based saturation level detector detects the exceeded saturation level, the polarity of the transformer's supply voltage changes, causing change in the sign of the flux density increment, while the welding current increases all the time. The advanced RSWS hysteresis control switches the transformer's supplied voltage according to the described pattern as long as the welding current does not reach its upper limit, which happens at the time $t_{4}$. When the upper limit for the welding current is reached, the supply voltage $u_{\mathrm{H}}=0$ is applied. The welding current starts to decrease. At the time $t_{5}$, it reaches its lower limit. The supply voltage with the same polarity as before the time $t_{4}\left(u_{\mathrm{H}}=-U_{\mathrm{DC}}\right)$ is applied again. At the time $t_{6}$, the saturation level detector detects the increased saturation level again, which causes change in the polarity of the transformer's supply voltage $u_{\mathrm{H}}=$ $U_{\text {DC. }}$ The RSWS operates as described, keeping the welding current between its lower and upper limits, until the welding cycle is completed. The transformer's supply voltage is set to 
$u_{\mathrm{H}}=0$ while the welding current decreases to value zero. The advanced hysteresis control controlled RSWS is ready for the new welding cycle.

\subsection{Test result}

The ANN structure used to detect the iron core saturation in the stand alone transformer cannot be applied when the transformer operates as a part of the RSWS. In the case of the stand alone transformer the ANN was used to supplement the calculated value of dynamic inductance $L_{\mathrm{d}}$ in order to evaluate the iron core saturation level. In the case of transformer operating as a part of RSWS the primary current $i_{1}$ supplemented by an ANN is used to detect the iron core saturation level. Thus the new ANN structure and learning method must be defined. This can be obtained with the proper dynamic model of the RSWS with included models of the advanced hysteresis control and the ANN based saturation level detector. Once the model is built, the proper structure of the ANN and learning method can be easily defined by running simulations with different ANN structures. The trial and error procedure was applied in the testing. As already mentioned, the ANN accumulates knowledge during the learning process. Fig. 13 shows both signals, which are involved in the learning process.

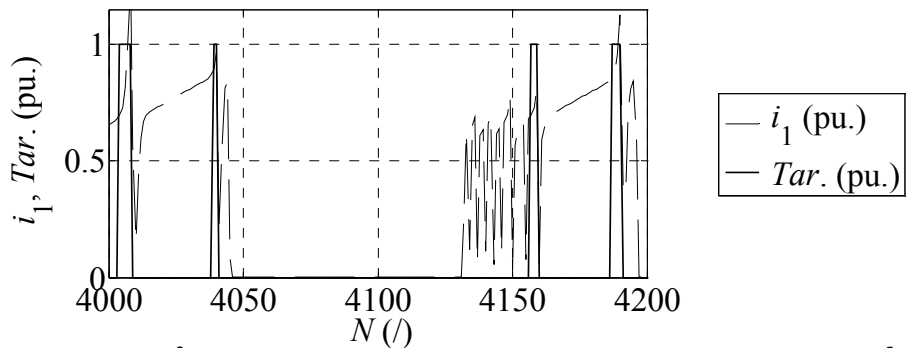

Fig. 13. The learning and targets signals in the case when the transformer operates as a part of the RSWS

The input learning signal (pattern) of the ANN in the learning process is the absolute value of the transformer's primary current $i_{1}(1 \mathrm{pu}=400 \mathrm{~A})$ obtained with the RSWS dynamic model. According to the saturation level in the iron core, the output learning signal (Tar.) was set to the value zero or one. The current spikes in the transformer's primary current clearly show that the iron core becomes highly saturated. In that case, the output of the ANN based saturation level detector must be set to the value one, which changes the polarity of the transformer's supply voltage in the RSWS controlled by the advanced hysteresis control. Fig. 13 shows learning signals during samples 4000 and 4200, while the number of all samples is 6000 .

The ANN output signals are very sensitive on the ANN net configuration, therefore an extensive testing of different net configurations was performed. The proper net structure can be defined with the proper model of a whole RSWS. The high computational effort required for simulations of the whole system forced us to apply the trial and error method in determining the ANN structure, instead of applying optimization techniques. The correlation coefficients between the target signal and calculated outputs were the root mean square errors (RMSE). The learning rates were controlled. Based on results of the extensive numerical analysis, the ANN structure with 30 neurons in first, 7 neurons in second and 1 
neuron in last layer was chosen (RMSE $=3.89 \%$ ). More or less neurons in the first layer gave worse RMSE. In addition for determining the ANN structure, the model was applied also for determining the most appropriate learning rule. From all learning rules tested, the resilient and Levenberg-Marquardt backpropagation algorithms gave the best RMSE values. However, the resilient backpropagation was adopted due to the lowest computational effort required.

As soon as the structure of the ANN and learning rule is defined, they can be applied on to the measured signals, while the ANN trained with the measured signals can be applied as a saturation level detector in the RSWS controlled by the advanced hysteresis control. Fig. 14 shows the output signals from the ANN for two different transformer's primary currents (absolute, per unit value, $1 \mathrm{pu}=400 \mathrm{~A}$ ) measured on the RSWS.

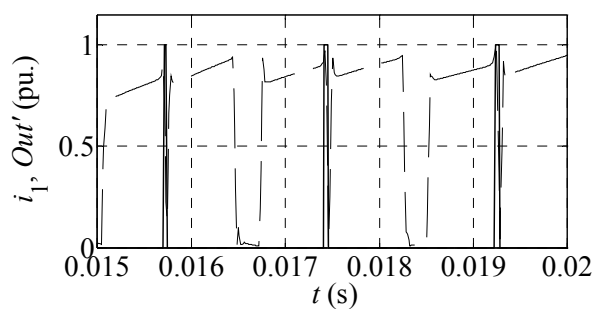

\begin{tabular}{|}
$-i_{1}$ (pu.) \\
$-O u t^{\prime}(\mathrm{pu})$.
\end{tabular}

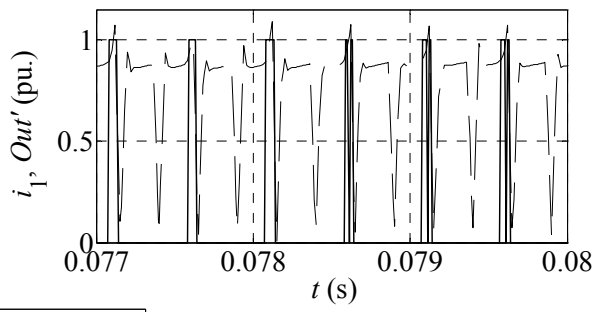

$t(\mathrm{~s})$

Fig. 14. Testing of the ANN with the different patterns

As soon as the ANN, through the characteristic form of the primary current, detects that the saturation level in the iron core is high enough, the value of the ANN output (Out') changes, causing change in the polarity of the applied supply voltage. This leads to the change in the sign of the magnetic flux density derivative. The magnetic flux density move in the opposite direction until the ANN detects increased saturation level again. The polarity of the applied supply voltage is changed again and the complete procedure is repeated.

\section{Conclusion}

This chapter deals with an evaluation of method appropriate for the iron core saturation level detection in welding transformer built into resistance spot welding system. The welding transformer is a part of a resistance spot welding system, where current spikes in the transformers primary current, caused by the iron core saturation, can cause the overcurrent protection switches-off of the entire spot welding system. For that reason the saturation level detection is an indispensable part of modern resistance spot welding systems. It makes the control of the iron core flux possible, which leads to better iron core exploitation and prevents over-current protection switch-offs. The main aim of this work is to present a reliable method for detection of the iron core saturation that does not require any additional sensor.

Firstly, an artificial neural network supplemented algorithm for detecting the saturation level in the iron core of a welding transformer is described. In order to prevent iron core saturation and current spikes in the primary current, the iron core saturation level detection, 
based on the dynamic inductances, is investigated. The drawbacks of the applied method could be effectively eliminated by using an artificial neural network as a supplement to the existing method.

After that the algorithm for detecting the saturation level in the iron core of the transformer operating as a part of the resistance spot welding system was presented. The proposed ANN based detector requires measurement of the welding transformer's primary current. The applied ANN is trained to recognize the waveform of the currents spikes which is used for saturation level detection. The applied ANN contains 3 layers with 30, 7 and 1 neuron in the first, second and third layer, respectively. It is trained by the resilient backpropagation rule using samples obtained by measurements and the dynamic model of the RSWS. Performances of the trained ANN were evaluated by the tests performed with the different measured samples. The results of the laboratory tests, shown in Fig. 13, are very promising and show reliable recognition of the iron core saturation.

\section{References}

Brown, B. M. (1987). A Comparison of AC and DC Resistance Welding of Automotive Steels. The Welding Journal, Vol. 66, No. 1, January 1987, pp. 8-23

Deželak, K.; Pihler, J.; Štumberger, G.; Klopčič, B. \& Dolinar, D. (2010). Artificial Neural Network Applied for Detection of Magnetization Level in the Iron core of a Welding Transformer. IEEE Trans. On Magnetics, Vol. 46, No. 2, February 2010, pp. 634-637

Deželak, K.; Klopčič, B.; Štumberger, G. \& Dolinar, D. (2008). Detecting Saturation Level in the Iron Core of a Welding Transformer in a Resistance Spot-Welding System. Journal of Magnetism and Magnetic Materials, Vol. 320, No. 20, October 2008, pp. 878883

Deželak, K.; Štumberger, G.; Klopčič, B.; Dolinar, D. \& Pihler, J. (2008). Iron Core Saturation Detector Supplemented by an Artificial Neural Network. Prz. Elektrotech., Vol. 84, No. 12, 2008, pp. 157-159

Hassoun, H. M. (1995). Fundamentals of Artificial Neural Networks, Library of Congress Cataloging, 0-262-08239-X, Massachusetts Institute of Technology

Hoyong, K.; Yunseok, K. \& Kyung-Hee, J. (1993). Artificial Neural Network Based Feeder Reconfiguration for Loss Reduction in Distribution Systems. IEEE Trans. On Power Delivery, Vol. 8, No. 3, 1993, pp. 1356-1366

Klopčič, B.; Dolinar, D. \& Štumberger, G. (2008). Advanced Control of a Resistance Spot Welding System. IEEE Trans. On Power Electronics, Vol. 23, No. 1, January 2008, pp. 144-152

Leon, F. \& Semlyen, A. (1994). Complete Transformer Model for Electromagnetic Transients. IEEE Trans. On Power Delivery, Vol. 9, No. 1, January 1994, pp. 231-239

Pihler, J.; Grčar, B. \& Dolinar, D. (1997). Improved Operation of Power Transformer Protection Using Artificial Neural Network. IEEE Trans. On Power Delivery, Vol. 12, No. 3, 1997, pp. 1128-1136

Ramboz, D. J. (1996). Machinable Rogowski Coil, Design, and Calibration. IEEE Trans. Instrumentation and Measurement, Vol. 45, No. 2, April 1996 
Sabate, J. A.; Vlatkovic, V.; Ridley, R. B.; Lee, F. C. \& Cho, B. H. (1990). Design Considerations for High-voltage High-power Full Bridge Zero Voltage-switching PWM Converter. IEEE Appl. Power Electron., Conference, 1990, pp. 275-284

Štumberger, G.; Klopčič, B.; Deželak, K. \& Dolinar, D. (2010). Prevention of Iron Core Saturation in Multi-Winding Transformer for DC-DC Converters. IEEE Trans. On Magnetics, Vol. 46, No. 2, February 2010, pp. 582-585 


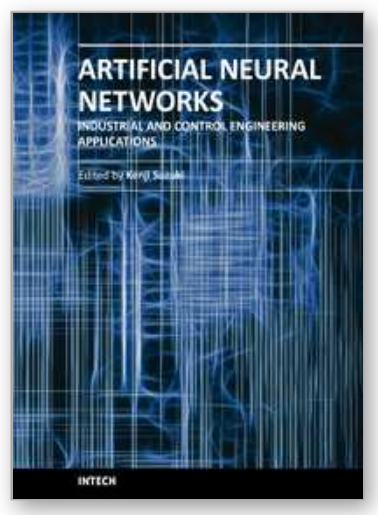

\author{
Artificial Neural Networks - Industrial and Control Engineering \\ Applications \\ Edited by Prof. Kenji Suzuki
}

ISBN 978-953-307-220-3

Hard cover, 478 pages

Publisher InTech

Published online 04, April, 2011

Published in print edition April, 2011

Artificial neural networks may probably be the single most successful technology in the last two decades which has been widely used in a large variety of applications. The purpose of this book is to provide recent advances of artificial neural networks in industrial and control engineering applications. The book begins with a review of applications of artificial neural networks in textile industries. Particular applications in textile industries follow. Parts continue with applications in materials science and industry such as material identification, and estimation of material property and state, food industry such as meat, electric and power industry such as batteries and power systems, mechanical engineering such as engines and machines, and control and robotic engineering such as system control and identification, fault diagnosis systems, and robot manipulation. Thus, this book will be a fundamental source of recent advances and applications of artificial neural networks in industrial and control engineering areas. The target audience includes professors and students in engineering schools, and researchers and engineers in industries.

\title{
How to reference
}

In order to correctly reference this scholarly work, feel free to copy and paste the following:

Klemen Deželak, Gorazd Stumberger, Drago Dolinar and Beno Klopčic (2011). Artificial Neural Network Applied for Detecting the Saturation Level in the Magnetic Core of a Welding Transformer, Artificial Neural Networks - Industrial and Control Engineering Applications, Prof. Kenji Suzuki (Ed.), ISBN: 978-953-307-220-3, InTech, Available from: http://www.intechopen.com/books/artificial-neural-networks-industrial-and-controlengineering-applications/artificial-neural-network-applied-for-detecting-the-saturation-level-in-the-magneticcore-of-a-weldi

\section{INTECH}

open science / open minds

\section{InTech Europe}

University Campus STeP Ri

Slavka Krautzeka 83/A

51000 Rijeka, Croatia

Phone: +385 (51) 770447

Fax: +385 (51) 686166

www.intechopen.com

\section{InTech China}

Unit 405, Office Block, Hotel Equatorial Shanghai

No.65, Yan An Road (West), Shanghai, 200040, China

中国上海市延安西路 65 号上海国际贵都大饭店办公楼 405 单元

Phone: +86-21-62489820

Fax: $+86-21-62489821$ 
(C) 2011 The Author(s). Licensee IntechOpen. This chapter is distributed under the terms of the Creative Commons Attribution-NonCommercialShareAlike-3.0 License, which permits use, distribution and reproduction for non-commercial purposes, provided the original is properly cited and derivative works building on this content are distributed under the same license. 